\title{
Testemunhos teóricos: a trajetória conceitual de Rita Schmidt
}

Theoretical Accounts: Rita Schmidt's Conceptual Inroads

\author{
Andrei dos Santos Cunha
}

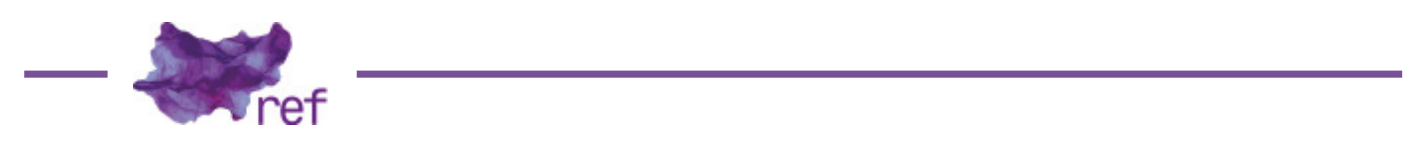

SCHMIDT, Rita Terezinha.

Descentramentos/Convergências: ensaios de crítica feminista.

Porto Alegre: UFRGS, 2017. 446 p.
quem pode dizer que conhece a generosidade só alguém que sentiu tudo isso no osso, o que é uma maneira de dizer a não ser que o osso esteja exposto (Angélica FREITAS, 2012, p. 59)

A autora dos ensaios desta coletânea, Rita Terezinha Schmidt, é professora do Programa de Pós-Graduação em Letras da Universidade Federal do Rio Grande do Sul e, ao longo de três décadas, construiu uma trajetória de muito destaque no âmbito dos estudos literários no Brasil. O presente volume dá ênfase à sua produção relacionada à crítica feminista, mas sua atuação acadêmica não se limita a esse tema, transitando ainda por questões relacionadas à Teoria da Literatura e à Literatura Comparada, para ficarmos apenas nos três principais eixos de sua carreira autoral.

Schmidt foi uma das fundadoras, em 1987, do Grupo de Trabalho "A Mulher na Literatura" da Associação Nacional de Pós-Graduação e Pesquisa em Letras e Linguística (ANPOLL). Esse grupo teve atuação decisiva no desenvolvimento dos estudos feministas relacionados à literatura no Brasil, e Schmidt foi uma das principais articuladoras do repertório teórico surgido nesse contexto, seja por meio dos muitos artigos que escreveu, seja por sua participação nos eventos e debates do grupo, ou ainda por sua opção de atuar como uma espécie de porta-voz e relatora desses eventos e debates, algo que Heloisa Buarque de Hollanda descreve da seguinte maneira no texto da orelha:

Desde o início, senti estar lendo um testemunho teórico, no sentido do conceito de Sandra Harding, da experiência como categoria de análise. Já no início, Rita politicamente dissolve sua autoria singular e define seu trabalho em sintonia com um trabalho coletivo acadêmico, desenvolvido por outras mulheres pesquisadoras [...]. (Heloisa Buarque de HOLLANDA, 2017, s/p)

O livro é dividido em duas partes, num total de dezenove artigos. A primeira parte do livro inclui textos de caráter mais teórico; a segunda é composta por artigos que abordam especificamente uma ou mais obras literárias. O texto mais antigo incluído no livro, "Mulher e literatura", teve sua primeira publicação em 1988, e trata principalmente da questão da representação da personagem feminina em obras de autores homens. O segundo texto, "Recortes de uma história: a construção de 
um fazer/saber" - cuja primeira versão foi publicada em 1999 - busca retomar os principais debates surgidos até então no âmbito do GT "A Mulher na Literatura", situando o desenvolvimento conceitual realizado coletivamente por essa comunidade crítica no contexto das discussões que ocorriam no mundo acadêmico da época. O texto aborda as diferenças entre uma crítica baseada em um conceito essencialista de sujeito feminino e outra, mais comprometida com os debates filosóficos do fin de siècle, que adotou a ideia de gênero como construto cultural e social. Em "Histórias de percurso", de 2006, Schmidt afirma que, inicialmente, a crítica feminista no Brasil se centrava na questão da representação da mulher na literatura, passando em seguida para a autoria feminina e se desestabilizando, em seguida, com a categoria "mulher", perdendo espaço frente a pressupostos pós-estruturalistas, pós-modernistas e da teoria de gênero.

O texto seguinte, "Revisitando a mulher na literatura: horizontes e desafios", volta aos mesmos temas dos dois artigos anteriores, ao recontar o surgimento do GT, que Schmidt considera, já nesse ponto de seu histórico (2010), como um projeto "bem-sucedido" (SCHMIDT, 2017, p. 108). Por outro lado, a autora aponta para um declínio da presença da literatura nos estudos feministas, e busca identificar algumas das causas desse impasse.

"Centros e margens: reflexões sobre a historiografia literária" é uma compilação de dois artigos, um de 1994 e outro de 2008, que começa com uma meditação sobre o novo significado que a história da literatura adquire quando se rejeita o binarismo arte/cultura, propondo uma historiografia que vá além da "contextualização" de obras literárias, na busca de uma "territorialização do literário na cultura" (SCHMIDT, 2017, p. 122). Em seguida, a autora defende uma reavaliação da história da literatura brasileira como reflexo de um autoritarismo excludente, com o objetivo de promover a recuperação de textos de autoria feminina. Ao fim, propõe uma breve história revisionista da literatura brasileira, na qual se destacam Júlia Lopes de Almeida e seu romance Memórias de Marta (1899) e Maria Firmina dos Reis e seu romance Úrsula (1859).

O texto seguinte da coletânea, "Cultura e dominação: pensando (d)as margens" é a reescritura de dois textos de 1997, e trata também da questão da autoria feminina no Brasil. 0 artigo traça um panorama do processo de formação do cânone brasileiro no século XIX, mostrando como as "obras eleitas são aquelas que vêm ao encontro de uma definição do literário sobre a qual já há um consenso prévio" (SCHMIDT, 2017, p. 153). Schmidt afirma ainda:

Mesmo que [as] preocupações [desses críticos] com o caráter nacional da literatura os tenham levado a abordagens histórico-sociológicas que tendiam a se concentrar na particularização do meio, o "critério de brasilidade", é preciso ponderar que essas preocupações estavam impregnadas pela internalização de um sistema cultural patriarcal em que o ideal de performance estética se achava concretizado nas obras modelares dos grandes mestres da literatura ocidental com os quais os críticos, por formação, eram familiarizados. (SCHMIDT, 2017, p. 154).

Como a passagem acima sugere, a coletânea apresenta uma forte densidade de "trechos citáveis". Com larga experiência tanto em debates teóricos como na docência, a técnica de redação de Schmidt demonstra um peculiar talento para a síntese de posições argumentativas por meio de frases de grande impacto, tanto do ponto de vista retórico como didático, o que facilita a compreensão de conceitos que, postos de outra maneira, tendem a ser vagos e de demorada absorção. Mesmo quando resultam de uma quantidade fora do comum de leituras e debates, as reflexões são apresentadas de forma clara e estruturada, com abundância de exemplos, e acompanhadas de sustentação empírica, revelando a vocação didática da autora.

"Do lugar do sujeito do feminismo: considerações sobre literatura, psicanálise e a questão do feminino" é resultado da compilação de um artigo de 1996 e de outro de 2002. Schmidt critica a ideia do "sujeito psicanalítico", considerando-o um construto que primordializa o masculino (SCHMIDT, 2017, p. 170), com "categorias sexualizadas de dominação e exclusão" (SCHMIDT, 2017 , p. 171). Isso constituiria uma das "dificuldades de apropriação da psicanálise para elaborar sobre a representação do sujeito feminino" (SCHMIDT, 2017, p. 184). Com relação à literatura, Schmidt reconhece no campo crítico brasileiro uma tendência para considerar a imagem da mulher escritora como histérica, o que teria contribuído para o apagamento da contribuição das mulheres nas historiografias oficiais da literatura escrita no Brasil.

O texto "A crítica feminista na mira da crítica", de 2000, é uma resenha de uma coletânea de artigos intitulada Brazilian feminisms, publicada no ano anterior, na Inglaterra. Schmidt desenvolve uma espécie de "defesa e ilustração" do feminismo brasileiro, e enfrenta a "imputação, feita às feministas no Brasil, de que suas análises revelam uma cegueira quanto às questões que envolvem raça e classe" (SCHMIDT, 2017, p. 204). Com óbvio conhecimento de causa, a autora afirma que esse tipo de generalização não dá conta dos diversos feminismos que há (ou houve) no Brasil desde os anos 1970. O artigo "Escrevendo gênero, reescrevendo a nação: da teoria, da resistência, da brasilidade", de 2002, retoma a atitude, digamos, mais combativa do texto anterior, de 2000 , e a direciona aos críticos da crítica feminista. Schmidt busca refutar, por exemplo, a tese de que o feminismo acadêmico é fruto da recepção da obra teórica de Foucault e Derrida nos Estados Unidos. 
"O projeto iluminista e os direitos da mulher" foi publicado inicialmente no contexto de um evento de 1991, ocorrido em Porto Alegre, intitulado "Caminhos para a liberdade: a Revolução Francesa e a Inconfidência Mineira". O texto busca demonstrar uma das teses centrais do pensamento de Rita Schmidt: o ideal de universalidade (em política, artes, cultura, sociedade) visa um apagamento de especificidades e, quando as diferenças são negadas, o que ocorre não é uma maior igualdade, e sim a consagração de um grupo específico como detentor do discurso de poder.

Em seu primeiro ensaio da segunda parte, "A história da literatura tem gênero? - anotações sobre o tempo (in)acabado de um projeto", um texto de 2014, Schmidt "discute a hegemonia do masculino na esfera da ciência e da cultura no ocidente e interroga a história literária a partir do contexto mais amplo das literaturas latino-americanas" (Susana Bornéo FUNCK, 2017, p. 14-15). A partir da análise de três livros de língua inglesa' dedicados a questões relacionadas à literatura da América Latina, Schmidt demonstra como essas obras, em suas ambições de inclusão e abrangência, relegam a discussão sobre questões feministas e de gênero a um plano secundário.

"Em busca da história não contada: ou o que acontece quando o objeto começa a falar", um artigo de 1999, apresenta à leitora brasileira o romance Moses, man of the mountain (1939), de Zora Neale Hurston. "A dissimulação em questão: visitando Dom Casmurro", de 2001, propõe a tese de que Capitu seria a "representante de uma nova mulher" (SCHMIDT, 201 7, p. 291), sugerindo que as tensões e instabilidades da trama machadiana deveriam muito à fase histórica de transições sociais em que elas são encenadas. "O fim da inocência: das Medusas de ontem e de hoje", de 2006, parte de uma ilustração para discutir a "metáfora-raiz" da Medusa em relação à tradição ocidental de associar o racional ao masculino. Os três textos seguintes tratam das obras Celeste (1893), de Maria Benedita Bormann; O Perdão (1910), de Andradina de Oliveira; e Perto do coração selvagem (1943), de Clarice Lispector. "Para além do dualismo natureza/cultura: ficções do corpo feminino", de 2012, traça um paralelo entre dois romances de autores homens - Madame Bovary (1857), de Gustave Flaubert; e Ana Karenina (1875), de Liev Tolstói - e a obra The Awakening (1899), da escritora estadunidense Kate Chopin, para revelar como o binarismo natureza/cultura se reflete nas escolhas representacionais desses escritores, em seu tratamento das personagens femininas. O texto inédito que encerra a coletânea, "Virginia Woolf: itinerários de vida e paixão", apresenta à leitora brasileira a vida e a obra de uma das autoras mais importantes para o pensamento de Schmidt. É um texto para muitos leitores, pois, se por um lado ele cumpre a função didática de excelente introdução ao universo de Woolf, não renuncia tampouco ao rigor acadêmico nem esconde a considerável medida de respeito, admiração e afeto que Schmidt nutre com relação à autora inglesa. Além disso, o ensaio demonstra como a crítica feminista já está presente na obra de Woolf e o quanto o seu posterior desenvolvimento deve a ela.

É uma pena que, como a maioria dos livros editados no Brasil, este volume não conte com um índice remissivo nem onomástico. A falta desses auxiliares de leitura se faz sentir porque as autoras, obras e temas discutidos são retomados inúmeras vezes, sempre com um enfoque diferente ou ampliado, refletindo a evolução do pensamento de Schmidt e os contextos políticos, sociais e culturais em que escreveu cada um de seus textos. Sendo esta também uma obra de referência, um índice onomástico seria extremamente útil para outras pesquisadoras identificarem, no corpo do texto, os diversos pontos em que os seus sujeitos de estudo são discutidos.

Nenhuma das escolhas temáticas de Rita Schmidt é fruto de acaso: elas revelam as origens acadêmicas da autora (que escreveu sua tese de doutorado sobre a obra de Hurston), assim como sua intenção política de dialogar com a tradição literária brasileira (Machado) e internacional (Flaubert, Tolstói, Chopin, Woolf) e com a filosofia ocidental (o mito da Medusa visto pela perspectiva feminista). Os textos sobre Bormann e Oliveira representam uma das lutas mais importantes travadas por Schmidt no âmbito da academia brasileira - a inclusão de obras de autoria feminina no debate sobre cânone e história literária. Por fim, é importante lembrar também que Clarice Lispector, hoje unanimidade nacional, foi, por muito tempo (no mínimo, até os anos 1990), proscrita do "panteão de autores brasileiros", considerada uma autora menor, e que sua ressignificação como ícone central do nosso imaginário passa por uma luta coletiva das feministas brasileiras, na qual a participação da própria Rita Schmidt foi crucial, tanto do ponto de vista político, como de sua prática na pesquisa e na docência.

\section{Referências}

FREITAS, Angélica. Um útero é do tamanho de um punho. São Paulo: Cosac Naify, 2012.

FUNCK, Susana Bornéo. "Apresentação". In: SCHMIDT, Rita Terezinha. Descentramentos/ Convergências: ensaios de crítica feminista. Porto Alegre: UFRGS, 2017. p. 11-15.

' São eles: The Cambridge History of Latin American Literature (1996); Literary Cultures of Latin America: a comparative history (2004) e Coloniality at large: Latin America and the postcolonial debate (2008). Cf. Schmidt (2017, p. 260-262) para a referência completa. 
HOLLANDA, Heloisa Buarque de. "Texto da orelha do livro". In: SCHMIDT, Rita Terezinha. Descentramentos/Convergências: ensaios de crítica feminista. Porto Alegre: UFRGS, 2017. s/p.

SCHMIDT, Rita Terezinha. Descentramentos/Convergências: ensaios de crítica feminista. Porto Alegre: UFRGS, 2017.

Andrei dos Santos Cunha (iD) 0000-0003-2826-748X

Doutorado em Literatura Comparada pela Universidade Federal do Rio Grande do Sul Tradutor literário (japonês-português). Atua no curso de Bacharelado Tradutor Português/Japonês e no Programa de Pós-Graduação em Letras da UFRGS, na linha de pesquisa Teoria, Crítica e Comparatismo. É pesquisador na área de Letras, com ênfase em Estudos de Tradução e Literatura Comparada.

Universidade Federal do Rio Grande do Sul, Instituto de Letras, Departamento de Línguas Modernas, Programa de Pós-Graduação em Letras

Avenida Bento Gonçalves, 9500 - Agronomia

91540-000 - Porto Alegre - RS - Brasil

+55 (51) 3308-6691 - ilelet2@ufrgs.br

andreicunha@gmail.com

\section{COMO CITAR ESSE ARTIGO DE ACORDO COM AS NORMAS DA REVISTA}

CUNHA, Andrei dos Santos. "Testemunhos teóricos: a trajetória conceitual de Rita Schmidt”. Revista Estudos Feministas, Florianópolis, v. 27, n. 1, e55495, 2019.

\section{CONTRIBUIÇÃO DE AUTORIA}

Não se aplica

\section{FINANCIAMENTO}

Não se aplica

\section{CONSENTIMENTO DE USO DE IMAGEM}

Não se aplica

APROVAÇÃO DE COMITÊ DE ÉTICA EM PESQUISA

Não se aplica

\section{CONFLITO DE INTERESSES}

Não se aplica

LICENÇA DE USO

Este artigo está licenciado sob a Licença Creative Commons CC-BY. Com essa licença você pode compartilhar, adaptar, criar para qualquer fim, desde que atribua a autoria da obra.

\section{HISTÓRICO}

Recebido em 25/02/2018

Aceito em 18/06/2018 